\title{
Examen especial a las operaciones administrativas y financieras de la cuenta transitoria viáticos, movilización y subsistencia del personal de la coordinación Provincial de pensiones del IESS- Loja en el periodo 01 de enero al 31 de diciembre de 2017
}

Special Review of the Administrative and Financial Operations in the Transitory Account of Travel Allowance for the Staff belonging to the Provincial Coordination from the IESS-Loja During the Period from 1 January to 31 December 2017.

\section{DOI: https://doi.org/10.33262/visionariodigital.v3i2.1.546}

Ruth Katherine Pucha Torres. ${ }^{1}$, Cecilia Ivonne Narváez Zurita. ${ }^{2}$, Juan Carlos Erazo Álvarez. ${ }^{3}$ $\&$ Mireya Magdalena Torres Palacios. ${ }^{4}$

\begin{abstract}
.
The implementation of a special review is considered as a subsequent control which verifies the financial statements presented by a public body or private capital. Thus, before the development of special audit techniques, these special reviews conclude that the information submitted has been processed in accordance with the provisions of the Law designed to achieve this.

In this context, this research aims to exercise accurate control over the payment of the administrative and financial operations in the transitory account of travel allowance for the staff belonging to the provincial coordination from the IESS-Loja during the period 1 January to 31 December 2017. After the implementation of the review, all movement on the account could be known, and it determined the proper execution of payment during the previous years. The level of how authorities planned their control
\end{abstract}

${ }^{1}$ Universidad Católica de Cuenca, Posgradista Maestría en Contabilidad y Auditoría, rkpuchat777@psg.ucacue.edu.ec

${ }^{2}$ Universidad Católica de Cuenca, Subdirección de Posgrado, Cuenca, Ecuador, inarvaez@ucacue.edu.ec

${ }^{3}$ Universidad Católica de Cuenca, Subdirección de Posgrado, Cuenca, Ecuador, jcerazo@ucacue.edu.ec

${ }^{4}$ Universidad Católica de Cuenca, Subdirección de Posgrado, Cuenca, Ecuador, mireya.torres@ucacue.edu.ec 
on the mentioned resources was also verified. Therefore, the degree of commitment to the given resources for the benefit of the community could be established.

Keywords: Special Review, internal control, Travel allowance, Subsistence

\section{Resumen.}

La realización de un examen especial, es considerado como un control posterior en una organización, el mismo que se encarga de analizar las afirmaciones contenidas en los estados financieros, que son presentadas por una organismo público o de capital privado, llegando a la conclusión, previo a la elaboración de pruebas de control y demás técnicas pruebas propias de la auditoria, de que si la información presentada ha sido desarrollada o procesada de acuerdo con lo dispuesto en cada norma o ley que se ha creado para el efecto.

En este contexto, el objetivo de la investigación es ejercer un control preciso sobre el pago de las operaciones administrativas y financieras de la cuenta transitoria viáticos, movilización y subsistencia del personal de la coordinación Provincial de pensiones del IESS- Loja en el periodo 01 de enero al 31 de diciembre de 2017. A partir de la ejecución del examen se pudo conocer el movimiento de la cuenta y determinar la adecuada ejecución del pago de años anteriores. Además, se verificó el nivel que las autoridades desarrollaron sus programaciones de control sobre los recursos antes mencionados, permitiendo establecer el grado de compromiso frente a los recursos que les han sido confiados para su normal desempeño en benéfico de la colectividad.

Palabras claves: Examen especial, control interno, viáticos y subsistencias.

\section{Introducción.}

La palabra auditoria, tiene su génesis en la práctica de registrar el cargamento que se hacían a los barcos mercantes, oyendo como la tripulación contaba en voz alta todos los artículos o demás insumos que se transportaban. En si procede la palabra procede de audire que significa "oír" en tiempos remotos el auditor era como el rey, garantizando que todos los impuestos fuesen correctamente recolectados y registrados a favor del rey supremo. Es importante señalar que lo que significó la palabra auditar en tiempos remotos sigue vigente aun en nuestros días, solo que se han creado los parámetros necesarios para mejorar su aplicabilidad (Arter, 2003).

Los orígenes de la auditoria se remontan a tiempos antiguos, ya que el hombre no solo sintió la necesidad de crear obras y registrar cada uno de sus actividades, sino también que las autoridades de ese entonces también sintieron la gran necesidad de tener el mínimo control 
de sus inversiones; es así que la auditoría paso de "oír" a la emisión de una opinión, obviamente basándose en estándares que guían su accionar (Viloria, 2004). También se señala en el estudio que una época muy importante para la auditoria fue la conocida como Edad Neolítica, Nueva Edad o Edad de piedra, ya que en países como Mesopotamia, Egipto o China y se tiene indicios del registro, y recordando que la auditoria es la examina precisamente esos registros.

Para Montilla y Herrera (2005) en los inicios de la profesión contable, los profesionales graduados en esta ciencia, eran los que se encargaban de todo el registro de las operaciones económicas y financieras de las organizaciones, sin un control independiente; pero como todas las ciencias evolucionan, la contabilidad expresa su máximo cambio precisamente con la auditoria, que consiste en evaluar los registros que son realizados por recursos humanos calificados, lo cual requiere tener la certeza absoluta de que se hayan cumplido todos los preceptos en la elaboración de los estados financieros de un periodo establecido.

En su estudio Villardefrancos, Álvarez y Rivera (2006) relatan a breves rasgos los antecedentes de la auditoria, así mencionan que la teneduría de libros aparece recién en Inglaterra en los años 1130, en Italia aparece en el siglo XV, y así continuamente en el resto de los países. El concepto moderno de auditoria surge en tiempos modernos debido a los fracasos financieros y económicos de las grandes empresas de Estados Unidos y Europa, debido a la falta de serenidad de los profesionales contables que no tuvieron el debido cuidado en las salidas de efectivo de las empresas, lo que las llevo a la quiebra, y por lo tanto se requería tener seguridad razonable de los hechos contables.

En este sentido, Mantilla (2016) señala la relevancia que tiene la auditoría financiera en tiempos modernos, razón por la cual se han incrementado de manera satisfactoria las investigaciones en este campo, a sabiendas que los resultados que brinda su aplicación sirve tanto para el habitad interno y externo de la empresa; a nivel interno se pueden tomar medidas que contribuyan a mejorar su situación actual en el corto o largo plazo y a nivel externo, los inversionistas podrán conocer las condiciones de la organización donde pretenden colocar capitales para ser producidos y que los mismos generen una rentabilidad relativamente segura.

Con la continua dialéctica de las ciencias, la auditoria también debe actualizar los métodos evaluativos, ya que como señala Fernández (2016) la auditoria tradicional que era en cierta forma cíclica y retrospectiva, ya no cumplía con todas las necesidades de las entidades que requerían los servicios, sobre todo el de contar en todo momento con información actualizada, exacta y libre de errores materiales o importantes, razón por la cual se hizo necesario el concepto de auditoria continua, la misma que hace referencia a que debe existir 
un departamento encargado de vigilar en todo momento los procedimientos de la empresa y de ser necesario mejorar los procedimientos internos.

Espinoza (2016) señala que la Norma Internacional de Auditoria NIA 401, establece de manera clara y precisa que el profesional que se encarga de desarrollar auditoria en cualquier dependencia, debe contar con suficientes conocimientos dentro de lo que compete a los conceptos de auditoría, control interno y procedimientos sustantivos y de cumplimiento, así como, sobre los diferentes riesgos que está expuesta la empresa y los riesgos que puede caer en su labor; las habilidades para solicitar la información pertinente como para informar los hechos encontrados es otra condición importante para desarrollar un trabajo oportuno y eficaz.

La auditoría es una evaluación posterior a los estados financieros, y consiste en verificar si los mismos han sido elaborados bajo las normativas y principios contables vigentes, lo que aseguraría su razonabilidad; es elaborada por un profesional idóneo en la materia con el propósito de brindar información pertinente que sirva para el establecimiento de medidas gerenciales. La auditoría financiera es la más conocida de todas las auditorias y de la cual se desprenden algunas, incluso es obligatoria su aplicación para ciertas empresas, en donde el auditor debe presentar a los organismos de control cualquier intento de fraude o hechos fraudulentos que se contrapongan con las disposiciones legales (Ocampo, Trejos y Solarte, 2010).

Para Cerezo (2013) el término auditoría contable remite a un proceso contable que debe ser examinado en su conjunto para establecer la razonabilidad de los saldos en concordancia con las normativas contables, sirviéndose para ello de la evidencia necesaria para su informe final, que será presentado a todos los usuarios para la toma de decisiones gerenciales. La evidencia a su vez se la obtiene de las pruebas que realice el auditor, con el tino suficiente para poder recopilar la información y la misma sirva para fundamentar su opinión.

La Contraloria General del Estado (2001) señala como objetivo básico de la auditoría examinar los estados financieros es el comunicar sobre el cumplimiento de normas en los informes contables que emiten las administraciones de las dependencias que pertenecen al estado; adicionalmente persigue los siguientes:

$\checkmark \quad$ Inspeccionar el uso de los bienes de una entidad, programa o proyecto, para establecer como se administran, evaluación de metas y objetivos cumplidos en base a normativas establecidas.

$\checkmark \quad$ Verificar que controles se hacen en las entidades. 
$\checkmark$ Comprobar el desempeño de las normativas procedentes de organismos de control.

$\checkmark$ Fomentar el desarrollo de sistemas de información.

$\checkmark$ Brindar recomendaciones factibles de asimilar.

En su análisis de la Norma Internacional de Auditoria NIA 200 y 320, Mendoza (2009) señala que el objetivo de la auditoría financiera es que el auditor emita un criterio sobre si los estados financieros han sido elaborados en relación de todo lo importante y de acuerdo a las normas y principios contables; seguidamente señala que el auditor reduce el riesgo al diseñar procedimientos que le sirvan para obtener evidencia suficiente y competente para extraer conclusiones razonables en las que fundamenta su opinión. Se obtiene una seguridad razonable cuando el profesional de la auditoria logra reducir el riesgo de auditoria, a niveles bajos que son aceptables en el entorno donde se desenvuelve la organización.

En la opinión de Yáñez y Ávila (2015) uno de los campos donde existe la figura del dictamen, es precisamente en la contaduría pública y privada, específicamente en lo relacionado a los estados financieros que son presentados por una unidad económica y donde le auditor tiene como objetivo principal, la emisión de un juicio evaluativo de la razonabilidad de las afirmaciones que constan en los informes contables, que son de exclusiva encargo de la gerencia de la organización, este juicio evaluativo es lo que se conoce como dictamen de los estados financieros y para lo cual el auditor debe tener la suficiente evidencia para emitirlo.

La auditoría a los estados financieros es importante ya que el auditor independiente desarrollará su evaluación con base en pruebas selectivas que le permitirán conocer las debilidades de la organización en todo su conjunto, lo que servirá para delimitar las estrategias pertinentes para solventarlas; de la misa forma es relevante su aplicación, en virtud a que el auditor, junto con el dictamen de los estados financieros, emite un informe sobre la seguridad que brinda los procedimientos internos que utiliza la entidad, evaluando su operatividad, tomando decisiones para fortalecerlos y consecuentemente mejorar las afirmaciones que se presentan en los estados financieros (Escalante y Hulett, 2010).

Según Palazuelos, Herrero y Montoya (2017) la crisis económica y financiera que aun afecta a un sin muero de empresas en todo el mundo, es lo que fortalece la importancia de la auditora en la verificación de las afirmaciones presentadas, debido que se requiere un aporte, que de fidelidad de la información presentada por las organizaciones, y así, los grupos inversionistas puedan estar seguros que sus recursos serán manejados de manera eficiente con el fin de maximizar los activos y llegar a los objetivos de rentabilidad propuestos; cabe mencionar además, que una información auditada sirve para la toma acertada de decisiones eficaces, con base en hechos objetivos de su realidad. 
La auditoría se clasifica de diferentes formas y dependiendo de lo que se desea indagar; Vega (2006) manifiesta que la auditoria es interna y externa en función del profesional que la lleva a efecto; según su alcance se clasifica en obligatoria o voluntaria; entre otras clasificaciones que pretenden examinar procesos que tiene relación directa con la organización.

Independientemente del tipo de auditoría que se vaya a desarrollar, el sujeto que es el responsable de llevarla a cabo debe disponer en todo momento la ayuda de normativas que guíen su accionar con el fin de dar un trabajo que contribuya a los intereses y mejoras de la empresa.

Auditoria interna.- es el tipo de evaluación que se práctica como un mecanismo de defensa por la propia empresa o entidad, encargando a un departamento específico para que realice una valoración independiente de las actividades designadas a las demás área de la empresa, razón por la cual debe funcionar como una unidad que agrega valor y a través de sus pronunciamientos mejorar las operaciones, actividades y procesos internos de la empresa, contribuyendo de una forma directa al acatamiento de los objetivos o aspiraciones proyectadas (Velázquez y Sánchez, 2015). Al igual que otras auditorias, el responsable de ejecutarla debe ser independiente de sus funciones, aunque resulte un tanto difícil, ya que es parte integral del recurso humano de le entidad.

Auditoría externa. - es realizada por auditores independientes que ejercen su labor sin ningún compromiso con los responsables de procesar las operaciones o actividades del organismo auditado, normalmente en Ecuador es solicitada por la Superintendencia de Compañías para las empresas que están bajo su dirección. Adicionalmente, los inversionistas desean colocar sus capitales en entidades que presenten seguridad razonable sobre las cifras que la administración presenta a los usuarios; al tener una relación positiva entre la inversión, deuda y crecimiento de los últimos años y cuyos datos estén debidamente certificados por una firma auditora externa e independiente que abalice las afirmaciones y se pueda confiar en su situación actual (Rodríguez, 2011).

\section{Por su área de aplicación}

Auditoría financiera.- es aquella que contempla el estudio de las actividades, procesos, registros y estados financieros de un organización, por lo tanto el profesional auditor debe estar en pleno conocimiento de que en los estados financieros esta la base fundamental para desarrollar este tipo de auditorías; un paso importante que desarrolla el auditor es la determinación de la materialidad de los registros, construyendo una muestra para ser examinadas con todas las técnicas que la auditoria permite y con el fin de emitir un juicio, 
opinión o criterio profesional sobre la estructura de los informes contables (Silva y Chapis, 2015).

Auditoria gubernamental. - es desarrollada por la Contraloría General del Estado como órgano que está encargado de vigilar el correcto manejo de los recursos del estado, haciendo exámenes especiales de manera preventiva y sorpresiva, con el fin de asegurar que los fondos que se ha trasferido a cada dependencia que forma parte del aparato estatal, ha cumplido de manera fiel lo presupuestado y aprobado en los plazos pertinentes. Aldunate (2005) señala, que además de las atribuciones del control de legalidad y fiscal de la Contraloría, es obligación de todos los involucrados en el ámbito público el dar cumplimiento al deber constitucional de cumplió con lo establecido y aceptar la labor encomendada a esta dependencia.

Auditoria de gestión.- este tipo de auditoria se encarga de la evaluación de la calidad basada en la propia gestión de un proceso, determinando el cumplimiento de metas proyectadas; los objetivos de este tipo de auditoria se los resume a través de la determinación de la conformidad o no de una actividad con los especificaciones establecidas; evaluar la eficacia del proceso, analizando cuantos de los objetivos se han cumplido y de qué manera se han logrado; identificar las oportunidades de mejoramiento, satisfacer los requisitos que solicitan los organismos de control y evaluar si el proceso puede permanecer dentro de la empresa; es determinante para delimitar si la administración del ente está en capacidad de asumir el reto y si los recurso están siendo administrados de manera oportuna (González, Hernández, Fernández y Padrón, 2015).

Auditoria forense. - es aquella especializada en descubrir sobre desvíos de liquidez en operaciones ajenas al ente, abriéndose un amplio espacio al campo de la investigación oportuna, que va un poco más allá del simple hecho de comprobar que verdaderamente existió un delito (Villalobos, 2011). De la misma forma Flóres, Gallego, Hérnandez (2015), señala que la auditoria forense tiene como objetivo la revisión de procesos con el fin de detectar procesos ilícitos dentro de la empresa, para lo cual se hace necesario utilizar herramientas que son especializadas, que contribuyan a conseguir los datos elementales para ser analizados por el auditor. Este tipo de auditoria se ha fortalecido en los últimos años, debido a las continuas denuncias de malversaciones de fondos por parte de los administradores.

Auditoria tributaria. - la auditoría tributaria según Flores (2012) es el conjunto de principios, procedimientos y actividades que se destinan a la verificación objetiva de que una empresa ha aplicado de manera razonable las normas y principios contables, si se han interpretado de manera eficiente las leyes tributarias y consecuentemente si se han elaborado de manera correcta las declaraciones de impuestos de carácter obligatorio para el contribuyente. Adicionalmente expresa su opinión personal resaltando que es elaborada de 
manera independiente para corroborar que se ha cancelado todos los compromisos tributarios; este tipo de auditorías se han fortalecido en los últimos años, debido a que el gobierno a través del SRI, pretende disminuir los índices de evasión tributaria y así poder recaudar más ingresos estatales.

Auditoria de Marketing. - es otro tipo de investigación que se aplica a los entes contables, tiene relación directa con la auditoría operacional o de gestión, ya que, a través de técnicas oportunas y apropiadas, se evalúa la pertinencia, eficiencia y efectividad de la información existente en la compañía o entidad auditada, permitiendo a su vez lograr y fortalecer de forma continua el desempeño de los componentes de mercadeo, así como las políticas internas de la organización. En algunos casos es imprescindible la utilización de indicadores de gestión para evaluar el logro de objetivos programados (Oquendo, 2016).

Auditoria de cumplimiento de leyes y regulaciones.- Blanco (2003) Este tipo de cumplimiento dentro de una auditoria ayuda a determinar mediante las leyes y las regulaciones los fraudes y las desviaciones de la información de las empresas a través de los exámenes especiales a las operaciones financieras, administrativas y económicas de acuerdo a lo estipulado en las normas vigentes, mediante los procedimientos aplicables en dicho examen para determinar los procedimientos que se utilizan en el control interno. Para prevenir y detectar los fraudes, la responsabilidad de los directores de la entidad es mucho mayor, ya que sobre ellos recaerá el mayor peso por el manejo inadecuado de los bienes, razón de ello, el establecimiento del control de mantenimiento de políticas, es vital para ayudar al cumplimiento de los objetivos.

Examen especial.- se caracteriza por ser una evaluación profesional a una sola parte de los estados financieros, se da principalmente cuando los organismos que ejercen una revisión de los bienes públicos como la CGE se desea conocer el manejo eficiente de ciertas partidas específicas que por diversas razones tienes a tener desconfianza en su manejo adecuado, o simplemente por denuncias debidamente fundamentadas (Contraloria General del Estado, 2001).

A consideración de la auditoria, uno de las formas de auditar más comunes en el sector público es precisamente el examen especial a los rubros de las partidas presupuestarias de ingresos y gastos de las entidades públicas, ya que su ejecución supone un menor costo en dinero y tiempo para conocer los resultados de la gestión emprendida sobre los valores transferidos a las entidades que pertenecen al sector público, alineando el posicionamiento con la (Contraloria General del Estado, 2001).

Según la Contraloria General del Estado (2001) el EE alcanza la investigación y el examen de un fragmento de las actividades u sistematizaciones realizadas por una entidad de carácter público con sucesión a su realización, con el propósito fundamental de comprobar el 
acatamiento de los preceptos aplicables, situación que le permite al auditor, diseñar el conveniente informe, que incluya las conclusiones principales, reflexiones y sugerencias. El EE puede ser a una sola cuenta o grupo de cuentas que se desee indagar, siempre y cuando se tenga la debida autorización de las autoridades pertinentes, jamás, sin su consentimiento.

El examen especial es una forma de auditar, pero con la particularidad que se examina una parte o solo un grupo de rubros, de los cuales la empresa desea obtener la certeza absoluta que han sido procesados de manera eficiente por los responsables de presentar las afirmaciones en los estados financieros. Izquierdo (2013) señala que los auditores pueden utilizar datos históricos para filtrar información, y así definir el alcance del examen a realizar en la organización, ya que bien pueden analizar solamente un determinado proceso o grupo de clientes, o a su vez se puede establecer una evaluación a un determinado departamento del cual se tiene sospechas sobre su funcionamiento.

Según la Ley Orgánica de la Contraloría General del Estado, LOCGE en su art. 19 conceptualiza al EE como una herramienta que permite verificar que las entidades que comprende todo el aparato estatal han realizado sus operaciones respetando los dictaminado en las leyes emitidas para cada aspecto o actividad encomendada a ellas, su aporte es muy significativo para determinar desvíos de dinero o actuaciones en beneficio privado y no colectivo.

\section{Fases del examen especial}

\section{a) Planeación de la Auditoria}

Sotomayor (2008) señala que, para llevar a cabo la evaluación, el auditor debe contar con la preparación académica suficiente y a su vez poner en practicar la ética profesional para conocer y poder planear una auditoria e identificar las funciones del personal de auditoria. La planeación implica establecer programas y determinar objetivos en cada etapa de cumplimiento para desarrollar y culminar cada actividad, esta planeación representa la administración y el desempeño de una auditoria en forma ordenada y con coherencia en sus diferentes secuencias operativas para ser guía de las actividades.

\section{b) Planificación preliminar del examen especial}

Sánchez (2006) relata que es necesario realizar una etapa preliminar del examen con el fin de conocer los aspectos más básicos de la empresa, entre ellos se tiene la actividad o giro del negocio, horarios de atención, ubicación, matriz y sucursales, el sistema contable utilizado, los principales proveedores, lista del personal que labora y que laboró en el departamento donde se desarrolla el examen especial y demás asuntos que son imprescindibles para conocer el ente contable en todos sus aspectos. Esta información dará al auditor una visión general de la organización, para ir formulando la estrategia a aplicar para la recopilación de las evidencias, que más adelante sustentaran el informe final. 


\section{c) Planificación especifica del examen especial}

La planificación específica del examen especial consiste en realizar una valoración del riesgo inherente y de control que tiene la empresa, así como la formulación de los procedimientos que se pretende realizar con el fin de encontrar evidencia requerida que fundamente el informe final presentado a los usuarios; los asuntos más relevantes de este apartado del examen especial son los siguientes, la oportunidad de los procedimientos de valoración de riesgos, el entendimiento del sistema de control interno SCI, para desarrollar los programas de auditoria y la necesidad inherente de reconsiderar la estrategia a ser aplicada (Blanco, 2012).

Enrique (2007) señala que la planeación se relaciona con los lineamientos de carácter general que regulan la disciplina de la auditoria, garantizando la cobertura de todos los rubros que se desea examinar; su propósito es establecer las acciones que el auditor debe desarrollar para instrumentar la auditoria de manera secuencial y ordenada, tomando en cuenta los plazos en cada operación a realizar con el tiempo establecido para la ejecución del trabajo de auditoria. La evaluación de los riesgos es otro factor que se toma en cuenta en la planificación, de ahí el auditor determina si es necesario la aplicación de pruebas sustantivas y de control.

\section{d) Ejecución}

Maldonado (2011) señala que la etapa de la ejecución es donde propiamente se contempla la obtención de evidencias y hallazgos, a través del uso de técnicas propias de la auditoria, estas evidencias que son puestas en el respectivo informe, son causa de una serie de pruebas sustantivas y de control que se realizan de manera coordinada y con la colaboración de los departamentos administrativos o productivos donde se esté desarrollando la evaluación. En esta fase del examen especial, es donde el auditor debe poner su mayor pericia para conseguir la mayor cantidad de información que le sirva para ir formulando su juicio profesional, siempre sustentado en los hallazgos significativos y evidencias suficientes.

\section{e) Informe o comunicación de resultados}

El informe de resultados es el documento que recoge todas las evidencias que se han ido sintetizando en los papeles de trabajo PT que ha realizado el evaluador, aquí el analista (auditor) debe informar sobre las situaciones adversas que ha revisado y no concuerdan con lo que estipulan las normas y principios contables vigentes. En su análisis Ruiz, Gómez y Carrera (2006) señalan que el cambiar o rotar un auditor en una empresa no siempre es una buena idea, ya que el criterio de cada uno es susceptible y puede mal interpretarse el trabajo realizado con anterioridad por otro auditor.

La última fase del examen especial es la entrega del informe final de la evaluación realizada a un rubro específico, para ello el auditor deberá contar con la debida evidencia que le permita afirmar que ciertas partidas han sido procesadas de forma errónea, no siguiendo la guía de 
las normas y principios contables que se han establecido para el efecto. Celante y Morales (2013) señalan que el auditor, en esta parte del examen especial, debe estar en la suficiente capacidad de brindar alternativas de solución al problema detectado, ya que de nada serviría informar sobre un problema sin dar un tipo de solución a los interesados.

\section{Papeles de Trabajo}

Madariaga (2004) afirma que se utilizan normas especiales para cada procedimiento, las mismas que deben garantizar los informes de auditoría de acuerdo a las normas establecidas durante el desarrollo del trabajo para llegar a conclusiones y presentar el informe. Los papeles de trabajo son documentación soporte que facilitan supervisar y administrar el trabajo de las auditorias futuras; son el respaldo donde el auditor ejecuta pruebas sustantivas (cálculos realizados por el auditor) y de cumplimiento (verificación de que se ha cumplido con las ordenanzas, leyes o demás normativas relacionadas) con el fin de llegar a determinar los hallazgos significativos y las evidencias suficientes para fundamentar su informe que será entregado a todos los usuarios de la información. Entre los papeles de trabajo se tiene:

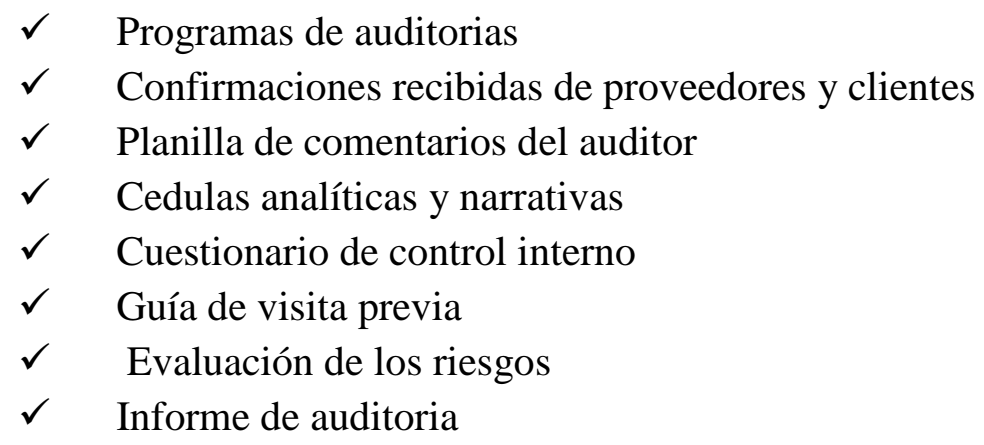

Flores (2012) refiriéndose a la NIA 230 Documentación de auditoria, considera que la documentación o papeles de trabajo están constituido por el material que el auditor prepara, obtiene y conserva en todo su trabajo de auditoria y pueden tomar la forma de datos contenidos en películas, medios electrónicos y otros medios conocidos. Los papeles ayudan en la planificación y desarrollo de la evaluación, supervisión y exploración del encargo y guardan la evidencia del trabajo realizado, que sirven para sustentar el informe final presentado a los que contratan los servicios de auditoría independiente.

\section{Control interno CI}

El control interno según Mantilla (2005), es un sumario ampliamente dirigido y razonado por los administradores donde los auditores son los que llevan a cabo el proceso donde se pueda ver si se ha alcanzado con los objetivos planteados por dicha empresa con el propósito de verificar si hay acatamiento de las normas y leyes que regulen el sistema del control interno durante una auditoria sirviendo de confiabilidad de dicha información durante el proceso de 
operación. Los procesos de los controles son manejados cada vez con la intención de llegar a obtener una gran variedad de soluciones a los problemas presentados, determinando la eficiencia y eficacia para llegar a reducir riesgos a futuro, dando confiabilidad a la presentación de estados financieros y cumplimiento de leyes y regulaciones.

Flores (2012) que cita a la NIA 400 señala que el CI es el agregado de estrategias e instrucciones adoptados y aplicados desde la gerencia para optimizar los recursos y lograr las metas programadas; los objetivos que persigue son los siguientes: salvaguardar los activos contra robos y uso deficiente, la prevención de detección de errores y fraudes considerables, lograr la exactitud e integridad de la información contable, oportuna presentación de información contable con base en normas internacionales, y que las actividades se desarrollen en armonía a lo que se espera desde las expectativas de los inversionistas.

Figura 1. Componentes de control interno

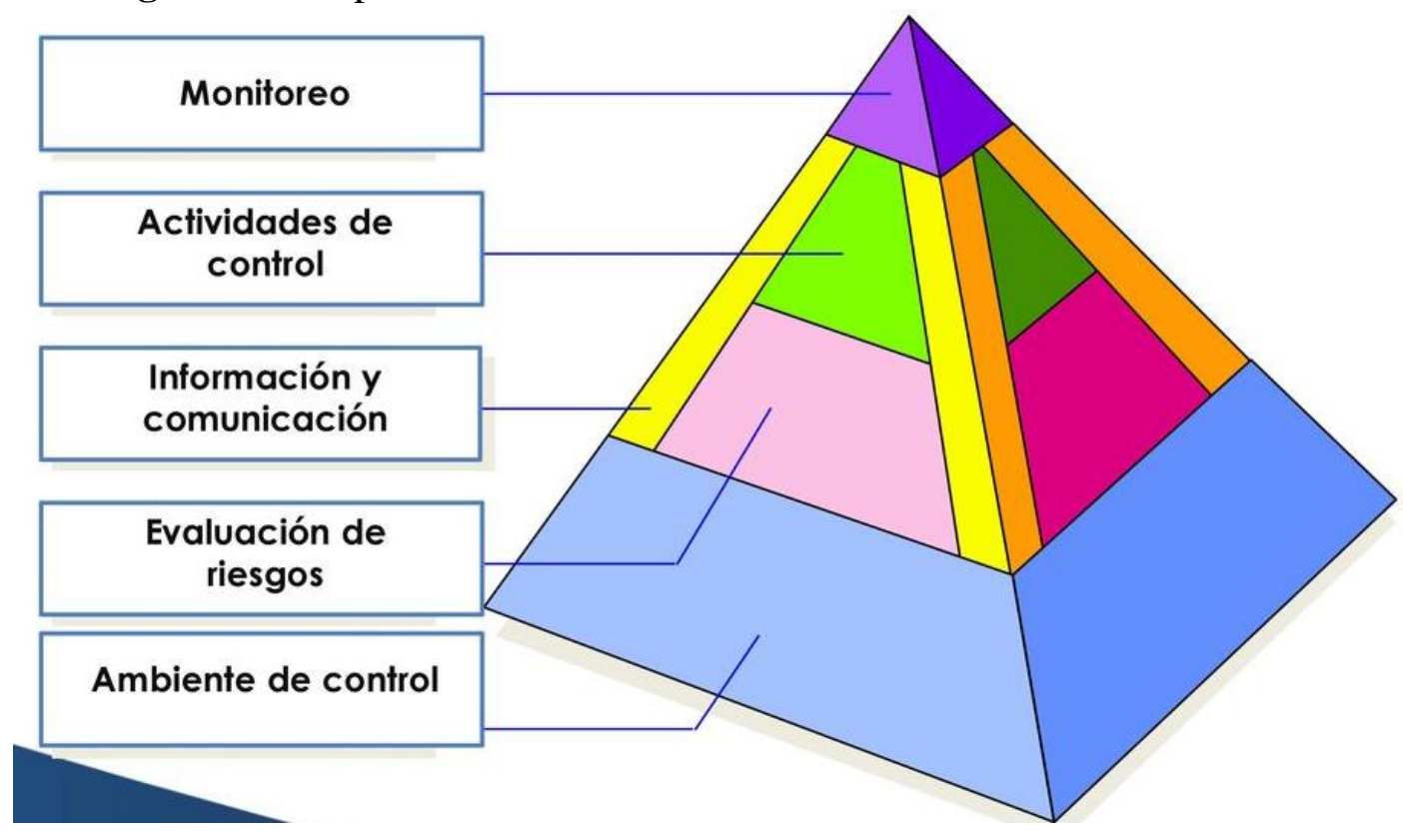

Fuente: Flores (2012)

Los componentes de control interno se aplican a todas las entidades públicas y privadas para llegar a cabo el cumplimiento de sus objetivos de manera eficaz y eficiente. Dentro de los cuales podemos citar los siguientes: Ambiente de control: determinan los valores y la integridad de los riesgos más sobresalientes dentro de un proceso de auditoría; Valoración de riesgos: se identifica los riesgos que se presentan en una entidad, Actividades de control: ayudan a verificar y revisar y constatar el desempeño de las funciones dentro de una entidad; Información y comunicación: se recopila la información veraz y oportuna, la comunicación efectiva debe ser amplia y oportuna; Monitoreo: los controles internos deben monitorearse para que se lleven a cabo el proceso de auditoría y tenga una valorización de la calidad; estos 
cinco componentes están direccionados a mejorar, contribuir y fortalecer las actividades dentro de la entidad.

\section{Metodologia}

En el presente artículo se definieron los aspectos metodológicos de la investigación que le confirieron credibilidad y fueron la base de las conclusiones a las cuales se llegó para realizar el examen especial a la cuenta transitoria de viáticos, movilización y subsistencia de la coordinación.

El enfoque fue mixto lo que supone la cohesión de los métodos cualitativo y cuantitativo, lo cual implicó utilizar las fortalezas de ambos tipos de indagación, combinándolas y tratando de minimizar sus debilidades al máximo. Por lo tanto, se aplicó una encuesta a los funcionarios que laboran en la parte administrativa y financiera de la coordinación provincial de prestaciones de pensiones con el objetivo de verificar si se está manejando correctamente la información contable. El alcance de la investigación fue descriptivo, por que caracterizó la realidad de la coordinación con respecto a la comprobación si se está aplicando correctamente la normativa del Ministerio de Trabajo como la normativa interna de la institución, para los procesos de pagos de viáticos, subsistencia y movilización. La finalidad del presente artículo consistió en realizar un examen especial a las operaciones administrativas y financieras de la cuenta transitoria viáticos, movilización y subsistencia del personal de la coordinación Provincial de pensiones del IESS- Loja en el periodo 01 de enero al 31 de diciembre de 2017 para llegar a verificar si el rubro que fue examinado objeto de estudio, poseía información contable oportuna.

En el presente artículo se utilizó el método histórico-lógico con el fin de poder conocer si se está cumpliendo con lo que está establecido en la normativa del Ministerio de Trabajo y la normativa interna de la institución con el pago de viáticos, movilización y subsistencia para los funcionarios de la coordinación. Además, se aplicó el método analítico sintético en el análisis del requerimiento de la institución para la ejecución de un examen especial de la cuenta transitoria viáticos, subsistencias y movilización.

Las técnicas utilizadas en la fase de diagnóstico fueron la encuesta, la entrevista, observación directa y revisión documental. El universo de estudio estuvo conformado por 11 funcionarios de la Coordinación Provincial de Pensiones del IESS - Loja.

\section{Resultados}

- Se pudo determinar que la cancelación del pago de viáticos, movilización y subsistencia a funcionarios de la coordinación no es cancelada oportunamente.

- Los anticipos de viáticos para cumplir con las comisiones asignadas no son otorgados de acuerdo a lo que establece la normativa del Ministerio del Trabajo. 
- La persona encargada de liquidación de viáticos no comunica oportunamente a los comisionados sobre los errores encontrados en las solicitudes de viáticos que presentan.

- Los documentos no se encuentran debidamente legalizados con firmas de respaldo.

- No existe un flujograma, ni un detalle de los funcionarios que salen de comisiones por parte de talento humano.

A partir de estos resultados se considera relevante la ejecución de un Examen especial a las operaciones administrativas y financieras de la cuenta transitoria viáticos, movilización y subsistencia del personal de la coordinación Provincial de pensiones del IESS- Loja en el periodo 01 de enero al 31 de diciembre de 2017.

Figura 2. Esquema de la propuesta

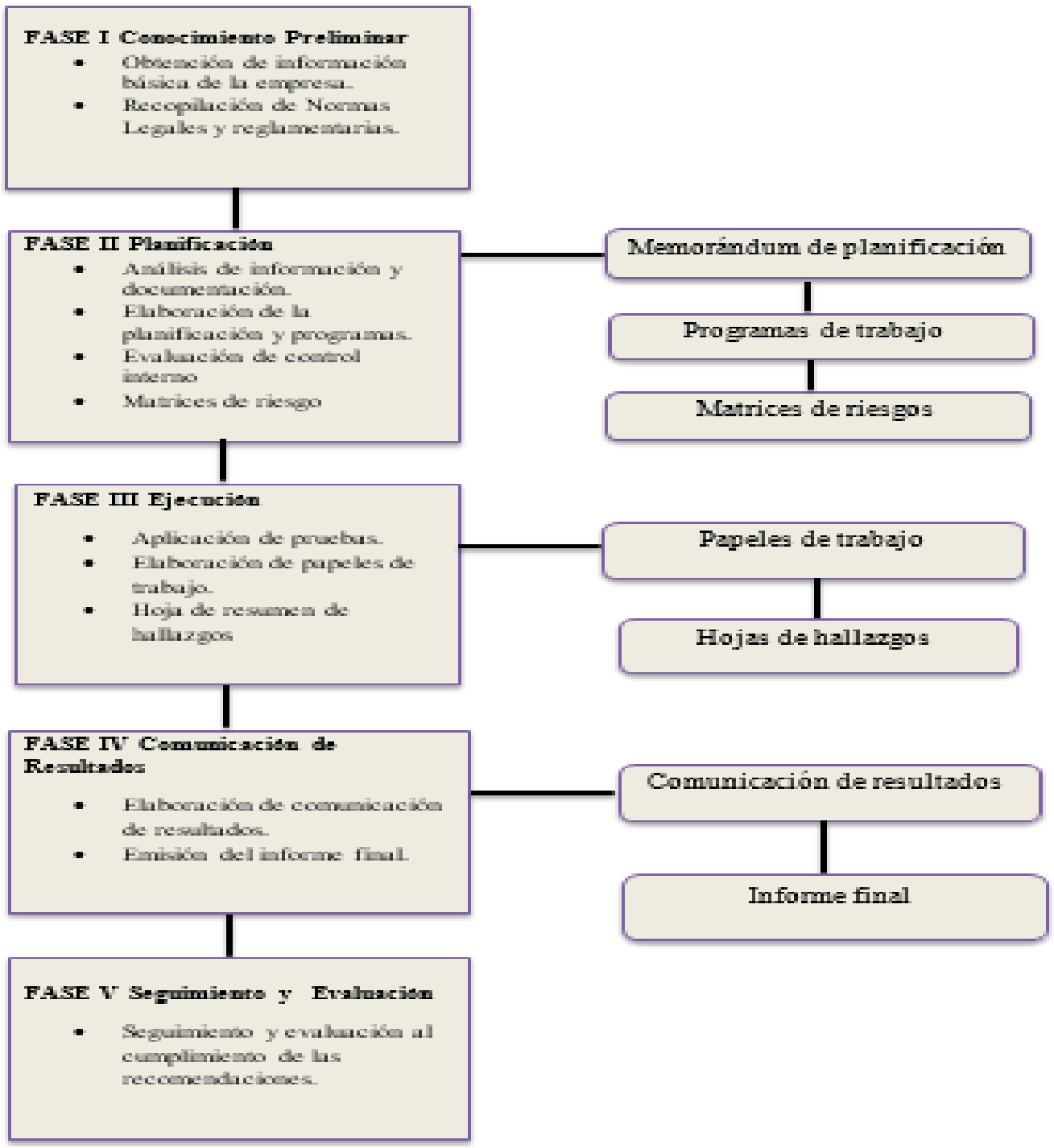

Fuente: Elaboración propia 
Srta. Ing.

NN

\section{AUDITORA}

Presente.-

En cumplimiento a los requisitos establecidos para la graduación de la Universidad Católica de Cuenca, dispongo a usted que, en calidad de auditora, realice un examen especial a las operaciones administrativas y financieras de la cuenta transitoria viáticos, movilización y subsistencia del personal de la coordinación Provincial de pensiones del IESS- Loja en el periodo 01 de enero al 31 de diciembre de 2017.

Los objetivos son:

- Verificar el grado de cumplimiento de las disposiciones legales, reglamentarias y demás normas aplicables en la utilización de los recursos de la cuenta viáticos, subsistencias y movilización del personal de la coordinación Provincial de Prestación de Pensiones, Riesgos del Trabajo, Desempleos y Fondos de Terceros, periodo entre el 1 de enero de 2017 y el 31 de diciembre de 2017.

- Determinar si el cálculo del pago de viáticos, subsistencia y movilización a los funcionarios de la coordinación son correctos de acuerdo a lo que establece la normativa del Ministerio de Trabajo con la normativa interna de la Institución

El equipo de trabajo estará conformado por:

Auditora: NN

Supervisora: NN

El tiempo estimado para la ejecución de esta acción de control es de 60 días laborables que incluye la elaboración del borrador del informe y la conferencia final.

Atentamente,

$\mathrm{NN}$

SUPERVISORA 
Tabla 1. Programa para la Planificación Preliminar

Instituto Ecuatoriano de Seguridad Social IESS- Loja

Examen especial a las operaciones administrativas y financieras de la cuenta viáticos, subsistencia y movilización del personal de la coordinación provincial de prestación de pensiones, riesgos del trabajo, desempleo y fondos de terceros

Del 01/01/2017 al 31/12/2017

\begin{tabular}{|c|c|}
\hline \multicolumn{2}{|c|}{ ACTIVIDADES } \\
\hline \multicolumn{2}{|c|}{ Conocimiento de la cuenta a examinar y su naturaleza jurídica. } \\
\hline \multicolumn{2}{|c|}{$\begin{array}{l}\text { Entrevistas con el personal involucrado en el examen especial, para informarles sobre su ejecución y a su vez } \\
\text { detectar información importante. }\end{array}$} \\
\hline \multicolumn{2}{|c|}{$\begin{array}{l}\text { Normativa e información relacionadas con el funcionamiento de la entidad en general y de la cuenta a } \\
\text { ser analizado; }\end{array}$} \\
\hline \multicolumn{2}{|c|}{$\begin{array}{l}\text { Estructura organizacional, ubicación de las instalaciones, detalle de funcionarios etc., unidades relacionadas } \\
\text { con la cuenta a ser analizada. }\end{array}$} \\
\hline \multicolumn{2}{|c|}{ Cédula presupuestaria de gastos del período de la cuenta a ser analizada, reformas, etc. } \\
\hline \multicolumn{2}{|c|}{ Informes de auditoría de la cuenta a ser analizada, cumplimiento de recomendaciones. } \\
\hline \multicolumn{2}{|c|}{ Saldo de la cuenta a ser analizado. } \\
\hline \multicolumn{2}{|c|}{ Documentos e informes requeridos para realizar el examen especial a la cuenta. } \\
\hline \multicolumn{2}{|c|}{ Conocimiento de las principales actividades, operaciones, instalaci } \\
\hline \multicolumn{2}{|c|}{ ades importantes de la cuenta a examinar. } \\
\hline \multicolumn{2}{|c|}{ Operaciones significativas de la cuenta a examinar. } \\
\hline \multicolumn{2}{|c|}{ Eventualidades importantes en la realización de la cuenta a examinar. } \\
\hline \multicolumn{2}{|c|}{ Usuarios de la información de la cuenta a examinar. } \\
\hline \multicolumn{2}{|c|}{ Procedimientos utilizados para la realización de la actividad de la cuenta a ser analizada. } \\
\hline \multicolumn{2}{|c|}{ Características de la cuenta a ser analizada. } \\
\hline \multicolumn{2}{|c|}{ Identificación de las principales políticas } \\
\hline \multicolumn{2}{|c|}{ Políticas para el manejo financiero de la cuenta a ser examina } \\
\hline \multicolumn{2}{|c|}{ Prácticas para la utilización de los recursos de la cuenta a ser examinada; } \\
\hline \multicolumn{2}{|c|}{ Políticas de manejo de presupuesto. } \\
\hline \multicolumn{2}{|c|}{$\begin{array}{l}\text { Determinación del grado de confiabilidad de la información financiera, administrativa y de operación, } \\
\text { así como la organización y responsabilidades de las unidades financiera, administrativa y de auditoría } \\
\text { interna. }\end{array}$} \\
\hline \multirow{2}{*}{\multicolumn{2}{|c|}{$\begin{array}{l}\text { Existencia de un coordinador administrativo financiero con sus responsabilidades y competencia. } \\
\text { Grado de centralización o descentralización de las actividades financieras en relación a la cuenta a ser } \\
\text { analizada. }\end{array}$}} \\
\hline & \\
\hline \multicolumn{2}{|c|}{ Responsabilidades de los funcionarios de la coordinación administrativa financiera. } \\
\hline \multicolumn{2}{|c|}{ Cambios de funcionarios en la administración y en sus responsabilidades. } \\
\hline \multicolumn{2}{|c|}{ Grado de independencia de funciones. } \\
\hline \multicolumn{2}{|c|}{$\begin{array}{l}\text { Comprensión global del desarrollo, complejidad y grado de dependencia del sistema de información } \\
\text { computarizado. }\end{array}$} \\
\hline \multicolumn{2}{|c|}{ Alcance del procesamiento automático de datos. } \\
\hline \multicolumn{2}{|c|}{ Grado de seguridad en el almacenamiento de información financiera. } \\
\hline $\begin{array}{l}\text { Elaborado por: RKPT } \\
\text { Revisado por: ICNZ }\end{array}$ & $\begin{array}{l}\text { Fecha: } 01 / 03 / 2019 \\
\text { Fecha: } 01 / 03 / 2019\end{array}$ \\
\hline
\end{tabular}


Tabla 2. Programa para la Planificación Específica

Instituto Ecuatoriano de Seguridad Social IESS- Loja

Examen especial a las operaciones administrativas y financieras de la cuenta viáticos, subsistencia y movilización del personal de la coordinación provincial de prestación de pensiones, riesgos del trabajo, desempleo y fondos de terceros

Del 01/01/2017 al 31/12/2017

\begin{tabular}{|c|c|}
\hline \multicolumn{2}{|c|}{ Procedimientos } \\
\hline \multicolumn{2}{|c|}{ Relación objetivo general y del reporte de planificación preliminar. } \\
\hline \multicolumn{2}{|c|}{$\begin{array}{l}\text { Estrategia de auditoría definida en la planificación preliminar y confróntela con el objetivo general de la } \\
\text { auditoría, determinando su coherencia. }\end{array}$} \\
\hline \multicolumn{2}{|c|}{ Estrategia a utilizar en la ejecución de la auditoría y comuníquela entre los miembros del equipo. } \\
\hline \multicolumn{2}{|c|}{ Principales componentes a ser evaluados durante la planificación específica. } \\
\hline \multicolumn{2}{|c|}{$\begin{array}{l}\text { Obtenga la información solicitada en la fase anterior: Funcionarios y unidades responsables, unidades } \\
\text { operativas relacionadas, principales actividades y operaciones, políticas y prácticas operativas y financieras, } \\
\text { comprensión de los sistemas computarizados. }\end{array}$} \\
\hline \multicolumn{2}{|c|}{ Evaluación del control interno } \\
\hline \multicolumn{2}{|c|}{ Componentes del control interno. } \\
\hline \multicolumn{2}{|c|}{ Principales unidades operativas y su estructura organizativa. } \\
\hline \multicolumn{2}{|c|}{ Riesgos inherentes existentes en relación con el ambiente de control de las principales actividades } \\
\hline \multicolumn{2}{|c|}{ Sistemas de registro e información. Identificar y registrar todas las transacciones válidas. } \\
\hline \multicolumn{2}{|c|}{ Todas las transacciones y operaciones para incluirlas en los informes. } \\
\hline \multicolumn{2}{|c|}{ Períodos para el registro e información, de tal forma que puedan ser analizados comparativamente. } \\
\hline \multicolumn{2}{|c|}{ Métodos para el registro consistente de las operaciones, en cantidades, volúmenes y valores. } \\
\hline \multicolumn{2}{|c|}{ Información sobre las transacciones realizadas, revelaciones en la información financiera y los reportes. } \\
\hline \multicolumn{2}{|c|}{ Políticas contables para el registro } \\
\hline \multicolumn{2}{|c|}{ Conocimiento de las políticas contables para los registros. } \\
\hline \multicolumn{2}{|c|}{$\begin{array}{l}\text { Comprensión del sistema de registro: Aspectos del sistema de registro utilizado para el control de las } \\
\text { operaciones; proceso de las transacciones; documentos de respaldo, registros financieros, procedimientos de } \\
\text { los datos e información; proceso para preparación de la información financiera y las revelaciones. }\end{array}$} \\
\hline \multicolumn{2}{|c|}{ Lista de informes preparados de la gestión financiera. } \\
\hline \multicolumn{2}{|c|}{ Sistema de información computarizado } \\
\hline \multicolumn{2}{|c|}{ Comprensión global del sistema. } \\
\hline \multicolumn{2}{|c|}{$\begin{array}{l}\text { Procedimiento de control: autorización de las transacciones, segregación y separación de funciones, } \\
\text { elaboración de documentos, registros e informes financieros, seguridad informática, reportes periódicos. }\end{array}$} \\
\hline $\begin{array}{l}\text { Elaborado por: RKPT } \\
\text { Revisado por: ICNZ }\end{array}$ & $\begin{array}{l}\text { Fecha: } 05 / 03 / 2019 \\
\text { Fecha: } 05 / 03 / 2019\end{array}$ \\
\hline
\end{tabular}


Tabla 3. Programa de auditoría

Instituto Ecuatoriano de Seguridad Social IESS- Loja

Examen especial a las operaciones administrativas y financieras de la cuenta viáticos, subsistencia y movilización del personal de la coordinación provincial de prestación de pensiones, riesgos del trabajo, desempleo y fondos de terceros

Del 01/01/2017 al 31/12/2017

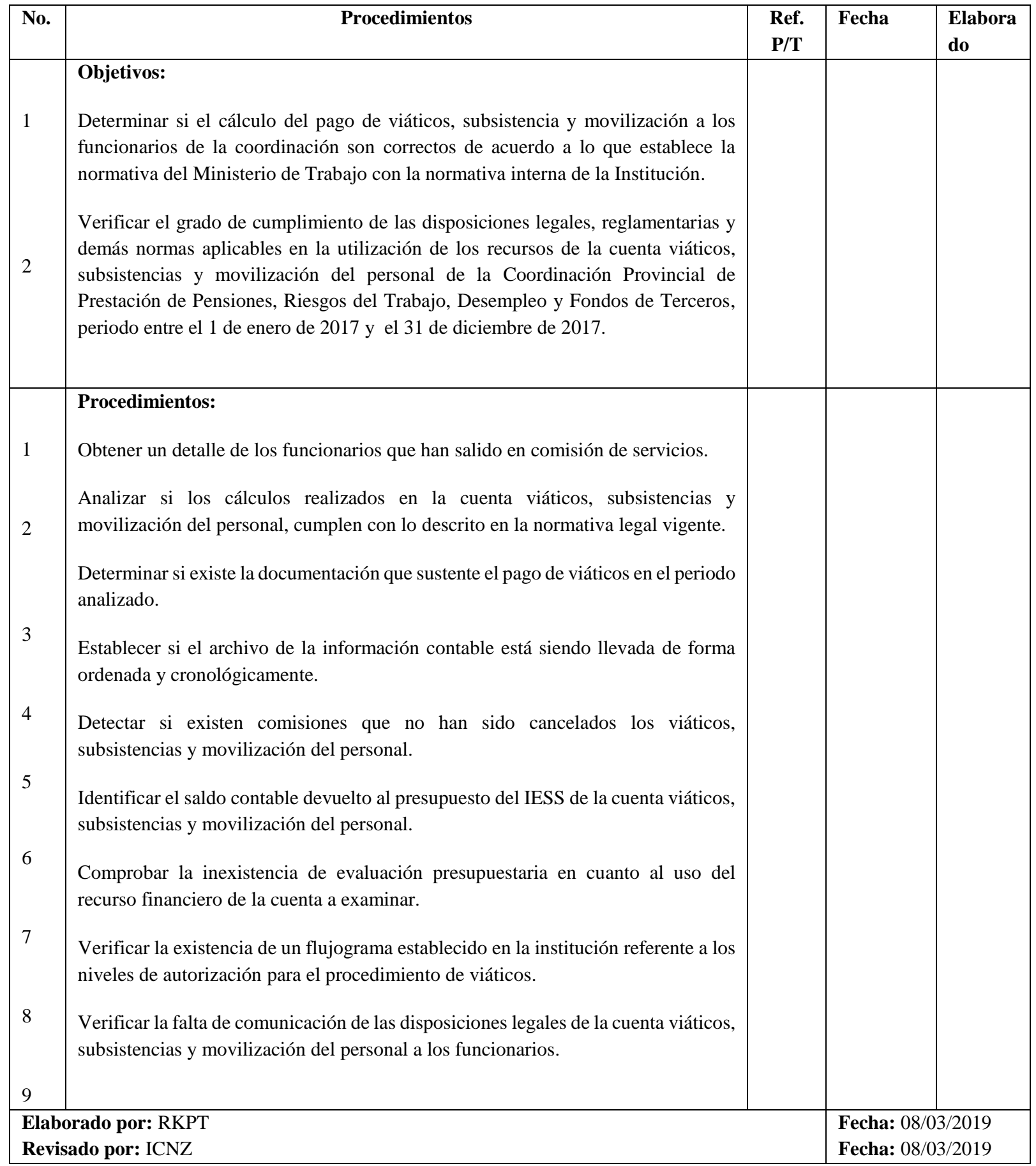


Tabla 4. Cuestionario de control interno

Instituto Ecuatoriano de Seguridad Social IESS - Loja

Examen especial a las operaciones administrativas y financieras de la cuenta viáticos, subsistencia y movilización del personal de la coordinación provincial de prestación de pensiones, riesgos del trabajo, desempleo y fondos de terceros

Del 01/01/2017 al 31/12/2017

\begin{tabular}{|c|c|c|c|c|c|c|c|}
\hline No. & Preguntas & SI & NO & N/A & PT & CT & Observaciones \\
\hline 1 & $\begin{array}{l}\text { Se mantiene un detalle actualizado de los } \\
\text { funcionarios comisionados y de los no pagados. }\end{array}$ & & $\mathrm{X}$ & & 11 & 0 & \\
\hline 2 & $\begin{array}{l}\text { El pago de los viáticos, subsistencias y } \\
\text { movilización del personal se lo hace mediante } \\
\text { transferencia bancaria. }\end{array}$ & $X$ & & & 11 & 11 & \\
\hline 3 & $\begin{array}{l}\text { El cálculo de los viáticos, subsistencias y } \\
\text { movilización del personal, se lo realiza conforme a } \\
\text { la normativa legal. }\end{array}$ & $\mathrm{X}$ & & & 11 & 11 & \\
\hline 4 & $\begin{array}{l}\text { El pago de viáticos se encuentra con la } \\
\text { documentación de sustento. }\end{array}$ & $X$ & & & 11 & 11 & \\
\hline 5 & $\begin{array}{l}\text { Los pagos de viáticos se han contabilizado luego de } \\
\text { realizar control previo y concurrente. }\end{array}$ & & $\mathrm{X}$ & & 11 & 0 & \\
\hline 6 & $\begin{array}{l}\text { Se utiliza todo el presupuesto aprobado de la cuenta } \\
\text { examinada. }\end{array}$ & & $\mathrm{X}$ & & 11 & 0 & \\
\hline 7 & $\begin{array}{l}\text { Se realiza la restitución del saldo de la cuenta de } \\
\text { viáticos no utilizado. }\end{array}$ & $X$ & & & 11 & 11 & \\
\hline 8 & $\begin{array}{l}\text { En la institución existe un reglamento interno de } \\
\text { viáticos. }\end{array}$ & $X$ & & & 11 & 11 & \\
\hline 9 & $\begin{array}{l}\text { Existe un flujograma establecido en la institución } \\
\text { referente a los niveles de autorización para el } \\
\text { procedimiento de viáticos. }\end{array}$ & & $\mathrm{X}$ & & 11 & 0 & \\
\hline 10 & $\begin{array}{l}\text { Se ha realizado una evaluación presupuestaria de } \\
\text { esta cuenta. }\end{array}$ & & $\mathrm{X}$ & & 11 & 0 & \\
\hline 11 & $\begin{array}{l}\text { La documentación de viáticos se encuentra } \\
\text { archivada de manera ordenada, numerada y } \\
\text { cronológicamente. }\end{array}$ & & $X$ & & 11 & 0 & \\
\hline 12 & $\begin{array}{l}\text { Los funcionarios han sido capacitados en las } \\
\text { normas y disposiciones legales sobre viáticos. }\end{array}$ & & $\mathrm{X}$ & & 11 & 0 & \\
\hline 13 & $\begin{array}{l}\text { Cuentan con un sistema contable que permita } \\
\text { obtener información oportuna para la toma de } \\
\text { decisiones. }\end{array}$ & $X$ & & & 11 & 11 & \\
\hline \multicolumn{5}{|c|}{ TOTAL } & 143 & 66 & \\
\hline \multicolumn{4}{|c|}{$\begin{array}{l}\text { Elaborado por: RKPT } \\
\text { Revisado por: ICNZ }\end{array}$} & \multicolumn{4}{|c|}{$\begin{array}{l}\text { Fecha: } 08 / 03 / 2019 \\
\text { Fecha: } 08 / 03 / 2019 \\
\end{array}$} \\
\hline
\end{tabular}


Tabla 5. Matriz de ponderación de la evaluación de control interno

Instituto Ecuatoriano de Seguridad Social IESS - Loja

Examen especial a las operaciones administrativas y financieras de la cuenta viáticos, subsistencia y movilización del personal de la coordinación provincial de prestación de pensiones, riesgos del trabajo, desempleo y fondos de terceros

Del 01/01/2017 al 31/12/2017

\section{Resultados de la Evaluación De Control Interno}

\begin{tabular}{|c|c|c|}
\hline \multicolumn{3}{|c|}{ Nivel de Confianza } \\
\hline Bajo & Moderado & Alto \\
\hline $15 \%-50 \%$ & $51 \%-75 \%$ & $76 \%-96 \%$ \\
\hline \multicolumn{3}{|c|}{ Nivel de Riesgo } \\
\hline Alto & Moderado & Bajo \\
\hline $76 \%-96 \%$ & $51 \%-75 \%$ & $15 \%-50 \%$ \\
& & \\
\hline
\end{tabular}

\section{Valoración}

NC: Nivel de Confianza

$\mathbf{N C}=\underline{\text { Calificación Total }(\mathrm{CT})} \times 100$

Ponderación Total (PT)

$\mathbf{N C}=\frac{66}{143} \times 100$

$\mathrm{NC}=46,15 \% \mathrm{BAJO}$

\section{Determinación de los niveles de riesgo}

NR: Nivel de Riesgo

NR: $100 \%$ - Nivel de Confianza

$\mathbf{N R}=100 \%-46,15 \%$

NR= 53,85 \% moderado

Como se puede observar el nivel de confianza corresponde al $46,15 \%$ considerado bajo y el nivel de riesgo $\mathbf{5 3 , 8 5} \%$ considerado moderado. 
Tabla 6. Matriz de Riesgo, cuenta: Viáticos, subsistencia y movilización

\begin{tabular}{|c|c|c|c|c|c|c|}
\hline \multirow{2}{*}{\multicolumn{2}{|c|}{$\begin{array}{c}\text { Composentey } \\
\text { subcomponeates }\end{array}$}} & \multicolumn{2}{|c|}{ Reespo y su fundameato } & \multirow{3}{*}{ Controles clare } & \multicolumn{2}{|c|}{ Enfoque de auditoria } \\
\hline & & Inherente & Control & & Pruebas de cumplimiento & Pruebas sustantivas \\
\hline \multirow{3}{*}{ 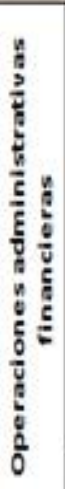 } & & Moderado & Bajo & & & \\
\hline & Vítios & 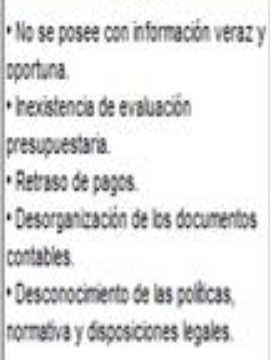 & 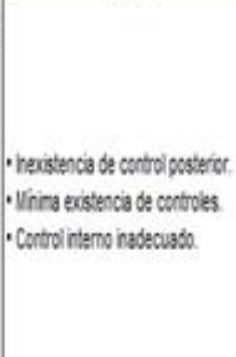 & 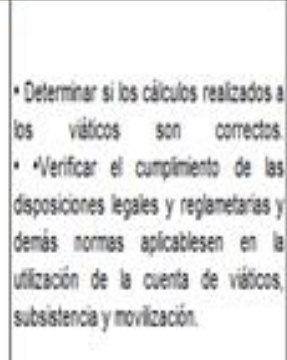 & 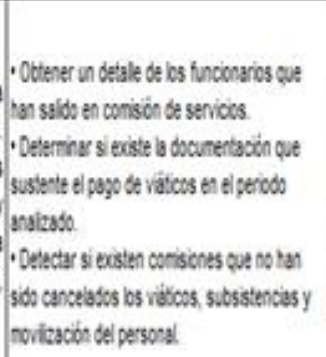 & 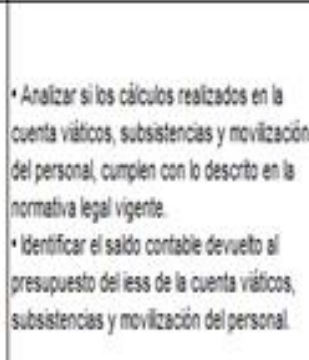 \\
\hline & & & & & & \\
\hline
\end{tabular}

Tabla 7. Matriz de verificación de pago de viáticos

\begin{tabular}{|c|c|c|c|c|c|c|c|c|c|c|c|c|c|c|c|c|c|}
\hline \multirow{2}{*}{ 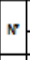 } & \multicolumn{2}{|c|}{ DIAS DE COMIIIÓN } & \multirow{2}{*}{ DESTINO } & \multirow{2}{*}{ MOTNO DE LA COMIIIÓN } & \multirow{2}{*}{ Ma vist. } & \multicolumn{4}{|c|}{ V. CANCBADO } & \multicolumn{5}{|c|}{ V. UUSTIFICADO } & \multirow[b]{2}{*}{ DIFER } & \multirow{2}{*}{\begin{tabular}{|c|} 
Obs ervaci \\
ón \\
\end{tabular}} & \multirow[b]{2}{*}{ OESERV. } \\
\hline & DESDE & HASTA & & & & VIAT. & Mov. & TRANS. & TOTAL & $70 \%$ & $30 \%$ & mov. & TRANS. & TOTAL & & & \\
\hline & & & & & & & & & & & & & & & & & \\
\hline \multirow[t]{2}{*}{1} & $17 / 1 / 2017$ & $18 / 1 / 2017$ & QUITO & Capacitadoun sobre Responsabillided Fatronal & 1 & 56,98 & 16,00 & 195,81 & 268,79 & 56,00 & 24,00 & 16,00 & 195,81 & 291,81 & 23,02 & $\sqrt{ }$ & \\
\hline & & & & & & & & & & & & & & & & & \\
\hline \multirow[t]{2}{*}{2} & $17 / 1 / 2017$ & $19 / 1 / 2017$ & QUITO & Capacitadon sobre Responsablildad Patronal & 1 & 64,34 & & 230,01 & 294,35 & 44,84 & 24,00 & & 230,01 & 298,25 & 4,50 & $\sqrt{ }$ & \\
\hline & & & & & & & & & & & & & & & & & \\
\hline 3 & $12 / 3 / 2017$ & $16 / 3 / 2017$ & QUTTO & Capesitadon sobre activos fljos & 3 & 98,00 & & 193,72 & 291,72 & 26,00 & 72,00 & $\cdot$ & 193,72 & 291,72 & & $\sqrt{ }$ & \\
\hline \multirow[t]{2}{*}{4} & 4/4/2017 & $5 / 4 / 2017$ & QUITO & Capastadon sobre actives flues & 1 & 77,69 & 16,00 & 177,76 & 271,45 & 53,69 & 24,00 & $16, \infty$ & 177,76 & 271,45 & & $\sqrt{ }$ & Faltant mas de lorallacion \\
\hline & & & & & & & & & & & & & & & & & \\
\hline 5 & $21 / 2 / 2017$ & $23 / 2 / 2017$ & QUITO & Reunion de trabalosobrs blenss de laredurac & 1 & 39,00 & & 281,10 & 220,10 & - & 39,00 & 10,00 & 170,92 & 219,92 & 0,18 & $\sqrt{ }$ & Valor an mas por parts del llauldador \\
\hline \multirow[t]{2}{*}{6} & 4/4/2017 & $6 / 4 / 2017$ & QUITO & Rounion ds trabajosobrs blanss de larpo durace & 1 & 73,09 & 16,00 & 205,12 & 294,21 & 34,09 & 39,00 & $16, \infty 0$ & 205,12 & 294,21 & & $\sqrt{ }$ & \\
\hline & & & & & & & & & & & & & & & & & \\
\hline \multirow{2}{*}{\begin{tabular}{|l|}
7 \\
8 \\
\end{tabular}} & $29 / 6 / 2017$ & $30 / 6 / 2017$ & QUITO & Reunion de trabajosn planta cantral & 1 & 130,00 & 16,00 & 249,08 & 395,08 & 91,17 & 39,00 & 16,00 & 249,08 & 395,25 & & $\sqrt{ }$ & Faltan trmas de lagalizezion \\
\hline & $1 / 6 / 2017$ & $2 / 6 / 2017$ & ZAPOTLLO & Tras adoa la trabajadora sodal a a provincla & 1 & 56,00 & . & - & 56,00 & 32,00 & 24,00 & - & - & 56,00 & & V & Faltan fimes de larallazion \\
\hline \multirow{2}{*}{9} & $5 / 7 / 2017$ & $7 / 7 / 2017$ & QUITO & Capecitadon sobre invartarlos de activos flues. & 1 & 66,62 & 16,00 & 162,22 & 244,84 & 42,62 & 24,00 & 16,00 & 262,22 & 244,24 & & $\sqrt{ }$ & Faltan firmes de lapalizacion \\
\hline & $2 / 6 / 2017$ & 2/6/2017 & CUENCA & Capestad on soore poros de host & . & . & . & 30,00 & 30,00 & - & - & . & 30,00 & 30,00 & & $\sqrt{ }$ & \\
\hline \multirow[t]{3}{*}{11} & $5 / 7 / 2017$ & $7 / 7 / 2017$ & QUITO & Capecitadon sobre invantarica de activos flus. & 1 & 66,62 & 16,00 & 162,22 & 244,84 & 42,62 & 24,00 & $16, \infty$ & 162,22 & 244,24 & & $\sqrt{ }$ & \\
\hline & & & & & & & & & & & & & & & & & \\
\hline & $22 / 10 / 2017$ & $24 / 10 / 2017$ & QUITO & Asistira raunion soors linsamisntes del PAC & . & . & 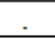 & 42,00 & 42,00 & - & . & . & 42,00 & 42,00 & & $\sqrt{ }$ & Fal tant rmas de lopallzacion \\
\hline \multirow[t]{2}{*}{23} & $14 / 9 / 2017$ & 16/9/2017 & QUITO & Capesitadon sobre alaplleativode pansiones & . & . & . & 46,00 & 46,00 & . & . & . & 46,00 & 46,00 & & $\sqrt{ }$ & Faltantrmas de lagall zacion \\
\hline & & & & & & & & & 4384,60 & & & & & 4444,65 & 27,52 & & Valor nocancel adosa las funce \\
\hline
\end{tabular}

Tabla 8. Matriz de diferencias entre egresos y pagos

\begin{tabular}{|c|c|c|c|c|}
\hline & BALANCE EORESOB & VALOR CANCELADO & DIFEREN CLA & $M E A E s$ \\
\hline PASAJESAL & 301553 & 301553 & 0.00 & \\
\hline VAA Toos Y & 139307 & 196907 & 24.00 & $M a r-17$ \\
\hline TOTALE 8 & 4408.8 & 4384.6 & 24.00 & \\
\hline
\end{tabular}




\section{Tabla 9. Cedula Narrativa}

Instituto Ecuatoriano de Seguridad Social IESS - Loja

Examen especial a las operaciones administrativas y financieras de la cuenta viáticos, subsistencia y movilización del personal de la coordinación provincial de prestación de pensiones, riesgos del trabajo, desempleo y fondos de terceros Del 01/01/2017 al 31/12/2017

Cálculos realizados en la cuenta viáticos, subsistencias y movilización del personal de acuerdo con lo descrito en la normativa legal vigente

\section{Comentario:}

Del análisis realizado se ha detectado que no se ha realizado un control previo por parte de los Responsables de Talento Humano, Contabilidad, Presupuesto y Coordinación Administrativa Financiera, observando que los valores no han sido calculados correctamente conforme lo estipula la normativa legal vigente del Ministerio de Trabajo, existiendo una diferencia de valor cancelado en menos de 27, 52 dólares y en más 0,18 centavos de dólar, además de la relación y revisión realizada entre los valores del balance de egresos y los valores cancelados existe una diferencia de 24,00 dólares correspondiente al mes de marzo de 2017.

Incumpliendo lo que establecen la Norma Técnica para el pago de viáticos, subsistencias, movilizaciones y alimentación, dentro del país para las y los servidores y las y los obreros en las instituciones del Estado, que en su artículo 11.- De la responsabilidad de las unidades financieras y administración de talento humano.

402-02 Control previo al compromiso. - Se denomina control previo, al conjunto de procedimientos y acciones que adoptan los niveles directivos de las entidades, antes de tomar decisiones, para precautelar la correcta administración del talento humano, financieros y materiales.

402-03 Control previo al devengado. - Previa a la aceptación de una obligación, o al reconocimiento de un derecho, como resultado de la recepción de bienes, servicios u obras, la venta de bienes o servicios u otros conceptos de ingresos, las servidoras y servidores serán los encargados del control.

Por lo expuesto anteriormente se ha ocasionado porque los responsables de Talento Humano, Contabilidad, Presupuesto y Coordinación Administrativa Financiera no han realizado un control previo adecuado a los procesos de cancelación de viáticos y movilización del personal de la institución conforme a la normativa legal.

\section{Conclusión:}

Inexistencia de un control previo adecuado por parte de los responsables de Talento Humano, Contabilidad, Presupuesto y Coordinación Administrativa, en los procesos de cancelación y contabilización de los viáticos y movilización del personal de la institución.

\section{Recomendación:}

A la Coordinadora Administrativa Financiera

Supervisar que las cancelaciones que se realicen al personal se realicen conforme a la normativa legal vigente. Al responsable de Talento Humano, Presupuesto y Contabilidad

Mantener un control previo adecuado de los procesos de cancelación de viáticos y movilización del personal de la institución.

\begin{tabular}{|l|l|}
\hline Elaborado por: RKPT & Fecha: 20/03/2019 \\
Revisado por: ICNZ & Fecha: 20/03/2019
\end{tabular}




\section{Informe del examen especial}

Se procedió a realizar el examen especial a las operaciones administrativas y financieras de la cuenta viáticos, subsistencia y movilización del personal de la coordinación provincial de prestación de pensiones, riesgos del trabajo, desempleo y fondos de terceros en el periodo 01 de enero al 31 de diciembre de 2017.

El Examen Especial se lo efectuó de conformidad con las Normas de Auditoria Generalmente Aceptadas (NAGA), Normas Ecuatorianas de Contabilidad (NEC), Normativa del Ministerio del Trabajo y normativa interna de la institución. Las mismas que requieren que el examen sea planificado y ejecutado para obtener evidencia razonable de los saldos de las cuentas examinadas que constan en los registros de la entidad, la información y la documentación no contienen exposiciones erróneas igualmente que las operaciones a las cuales corresponden se hayan desarrollado de conformidad con las disposiciones legales y reglamentarias, políticas y demás normas aplicables, constantemente se incluye pruebas y demás procedimientos que se consideró necesario en el proceso del examen.

Como criterio personal puedo decir que la ejecución de la cuenta de viáticos, subsistencia y movilización lo realizan en forma adecuada y según lo estipula la normativa del Ministerio del Trabajo y la normativa interna de la institución, sin embargo, se deberá considerar las recomendaciones que exponen al final del Examen Especial a fin de lograr la corrección de algunos errores en el control interno, lo que mejorará la eficiencia, efectividad de la coordinación.

\section{Conclusiones}

Una vez ejecutado el examen especial a las operaciones administrativas y financieras de la cuenta viáticos, subsistencia y movilización del personal de la coordinación provincial de prestación de pensiones, riesgos del trabajo, desempleo y fondos de terceros en el periodo 01 de enero al 31 de diciembre de 2017, se establece las siguientes conclusiones:

- En la coordinación provincial de prestaciones de pensiones no se ha realizado ningún tipo de auditoría financiera o examen especial, por lo tanto, no existen recomendaciones de auditorías anteriores.

- Se revisó la documentación que respaldan las operaciones administrativas y financieras, verificando la propiedad, legalidad y veracidad de los gastos efectuados por viáticos y subsistencias en el interior otorgados por el Instituto.

- Se evaluó el sistema de Control Interno para el proceso de viáticos y subsistencias, determinándose que existe un nivel de riesgo moderado por lo tanto el nivel de confianza es bajo lo que significa que faltan que falta control por parte del responsable de las liquidaciones de viáticos.

- El archivo institucional presenta inconvenientes en la obtención de información respecto al manejo de la liquidación de viáticos, no existe un detalle de las personas 
que han realizado comisiones de servicios por parte de talento humano y de contabilidad.

- Los Objetivos del trabajo se cumplieron, pudiendo establecer la legitimidad en el movimiento contable de la cuenta de gastos por viáticos, subsistencias y movilización en el interior.

\section{Referencias bibliográficas.}

Aldana, S., Vereda, F., Hidalgo-Alvarez, R., \& de Vicente, J. (2016). Facile synthesis of magnetic agarose microfibers by directed selfassembly. Polymer, 93, 61-64.

Arias, M. (2006). La información contable.

Arter, D. R. (2003). Auditorias de la calidad para mejorar su comportamiento (Tercera ed.). Madrid: Edigrafos S.A. Obtenido de https://books.google.es/books?hl=es\&lr=\&id=NpNx1iQVGwMC\&oi=fnd\&pg=PT10\&dq=1 ibro+de+auditoria\&ots=eqUPkUfpYn\&sig=BcpNX_2LKz2rTLtJZfkUhaPNOc\#v=onepage \&q=libro\%20de\%20auditoria\& $\mathrm{f}=$ false

Bhat, S., Tripathi, A., \& Kumar, A. (2010). Supermacroprous chitosan-agarose-gelatin cryogels. in vitro characterization and in vivo assesment for cartilage tissue engineering. Journal of the Royal Society Interface, 1-15.

Bossis, G., Marins, J., Kuzhir, P., Volkova, O., \& Zubarev, A. (2015). Functionalized microfibers for field-responsive materials and biological applications. Journal of Intelligent Material Systems and Structures, 1-9.

Contraloria General del Estado. (2001). Manual de Auditoría Financiera Gubernamental. Quito.

Cortés, J., Puig, J., Morales , J., \& Mendizábal, E. (2011). Hidrogeles nanoestructurados termosensibles sintetizados mediante polimerización en microemulsión inversa. Revista Mexicana de Ingeniería Química., 10(3), 513-520.

Dias, A., Hussain, A., Marcos, A., \& Roque, A. (2011). A biotechnological perspective on the application of iron oxide magnetic colloids modified with polysaccharides. Biotechnology Advances 29, 29, 142-155.

Estrada Guerrero, R., Lemus Torres, D., Mendoza Anaya, D., \& Rodriguez Lugo, V. (2010). Hidrogeles poliméricos potencialmente aplicables en Agricultura. Revista Iberoamericana de Polímeros, 12(2), 76-87.

García-Cerda, L., Rodríguez-Fernández, O., Betancourt-Galindo, R., Saldívar-Guerrero, R., \& Torres-Torres, M. (2003). Síntesis y propiedades de ferrofluidos de magnetita. Superficies y Vacío., 16(1), 28-31. 
Gómez, M. (2006). Introducción a la Metodología de la Investigación científica. Córdoba Argentina: Brujas.

Hurtado de Barrera, J. (2010). Metodología de la Investigación. Caracas: 4ta. edición Quiron Ediciones.

Ilg, P. (2013). Stimuli-responsive hydrogels cross-linked by magnetic nanoparticles. Soft Matter, 9, 3465-3468.

Lewitus, D., Branch, J., Smith, K., Callegari, G., Kohn, J., \& Neimark, A. (2011). Biohybrid carbon nanotube/agarose fibers for neural tissue engineering. Advanced Functional Materials, 21, 2624-2632.

Lin, Y.-S., Huang, K.-S., Yang, C.-H., Wang, C.-Y., Yang, Y.-S., Hsu, H.-C., . . . Tsai, C.-W. (2012). Microfluidic synthesis of microfibers for magnetic-responsive controlled drug release and cell culture. PLoS ONE, 7(3), 1-8.

Ruiz Estrada, G. (2004). Desarrollo de un Sistema de liberación de fármacos basado en nanopartículas magnéticas recubiertas con Polietilénglicol para el tratamiento de diferentes enfermedades. Madrid: Universidad Autónoma de Madrid. Departamento de Física Aplicada.

Song , J., King, S., Yoon , S., Cho, D., \& Jeong, Y. (2014). Enhanced spinnability of narbon nanotube fibers by surfactant addition. Fiberes and Polymers, 15(4), 762-766.

Tartaj, P., Morales, M., González-Carreño, T., Veintemillas-Verdaguer, S., \& Serna, C. (2005). Advances in magnetic nanoparticles for biotechnology applications. Journal of Magnetism and Magnetic Materials, 290, 28-34.

Viloria, N. (2004). Una aproximación a un enfoque holístico en auditoria. Actualidad Contable Faces, 86. Obtenido de http://www.redalyc.org/articulo.oa?id=25700909

Wulff-Pérez , M., Martín-Rodriguez, A., Gálvez-Ruiz, M., \& de Vicente, J. ( 2013 ). The effect of polymer surfactant on the rheological properties of nanoemulsions. Colloid and Polymer Science, 291, 709-716.

Zamora Mora, V., Soares, P., Echeverria, C., Hernández, R., \& Mijangos, C. (2015). Composite chitosan/Agarose ferrogels for potential applications in magnetic hyperethermia. Gels., 1, 69-80.

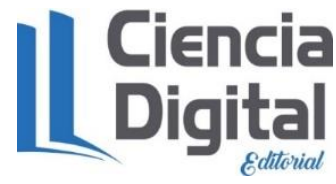




\section{PARA CITAR EL ARTÍCULO INDEXADO.}

Pucha Torres, R., Narváez Zurita, C., Erazo Álvarez, J., \& Torres Palacios, M. (2019). Examen especial a las operaciones administrativas y financieras de la cuenta transitoria viáticos, movilización y subsistencia del personal de la coordinación Provincial de pensiones del IESS- Loja en el periodo 01 de enero al 31 de diciembre de 2017. Visionario Digital, 3(2.1.), 60-85. https://doi.org/10.33262/visionariodigital.v3i2.1.546

\section{Ciencia}

El artículo que se publica es de exclusiva responsabilidad de los autores y no necesariamente reflejan el pensamiento de la Revista Ciencia Digital.

El artículo queda en propiedad de la revista y, por tanto, su publicación parcial y/o total en otro medio tiene que ser autorizado por el director de la Revista Ciencia Digital.
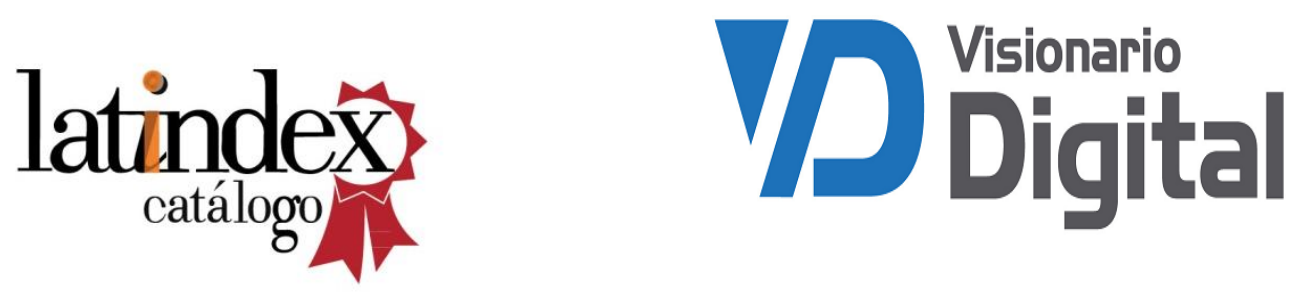